\section{RIMCIS}

\section{Hipatia Press}

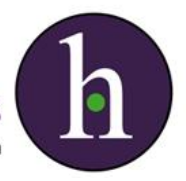

Instructions for authors, subscriptions and further details:

http://rimcis.hipatiapress.com

\title{
El Perfil del Votante del Cambio en España: De las Elecciones Europeas a las Generales del 20D
}

Irene Valero-Oteo ${ }^{1}$

1) Universidad del País Vasco - UPV/EHU, España

Date of publication: July $30^{\text {th }}, 2017$

Edition period: July 2017 - November 2017

To cite this article: Valero-Oteo, I. (2017). El Perfil del Votante del Cambio en España: De las Elecciones Europeas a las Generales del 20D. International and Multidisciplinary Journal of Social Sciences, 6(2), 107-136. doi: 10.17583/rimcis.2017.2395

To link this article: http://doi.org/10.17583/rimcis.2017.2395

\section{PLEASE SCROLL DOWN FOR ARTICLE}

The terms and conditions of use are related to the Open Journal System and to Creative Commons Attribution License (CC-BY). 


\section{Voters for the Change Profile in Spain: From European Elections to 20D General Elections}

Irene Valero-Oteo

Universidad del País Vasco (UPV/EHU)

\section{Abstract}

Global financial crisis, which became apparent on 2008, has had a devastating impact on social welfare of developed economies, including Spain. This state, combined with a sequence of another crisis, one of them institutional, that had remained dormant on Spanish society for decades, has raised doubts as to the ability of traditional politics to give solutions to population issues. In this context, Spain has witnessed deep changes in its political scene with the advent of two new political groups, which have made an strong entrance into the political territory and with the goal being to regenerate the politics of the country. This paper aims to analyze the profile of the voters who have chosen the new political groups, compared with the voters of traditional political groups, in order to observe differences and similarities between voters of new and old political groups.

Keywords: traditional political groups, new political groups, elections, change 


\section{Perfil del Votante del Cambio en España: De las Elecciones Europeas a las Generales del 20D}

Irene Valero-Oteo

Universidad del País Vasco (UPV/EHU)

\section{Resumen}

La crisis financiera mundial que se hizo visible en 2008 ha tenido consecuencias devastadoras para el bienestar social de las economías desarrolladas, entre ellas España. Esta situación sumada a otra serie de crisis, entre ellas institucional, que llevaban latentes en la sociedad española desde hace décadas, ha puesto en tela de juicio la capacidad de la política tradicional para dar solución a los problemas de la población. En este contexto, España ha visto transformado su escenario político con la irrupción en él de dos nuevas formaciones políticas, quienes han entrado con fuerza en el territorio político y cuyo objetivo es regenerar la política del país. En este trabajo lo que se intenta es analizar cuál ha sido el perfil de votante que ha apostado por las nuevas formaciones en comparación con los partidos tradicionales, con objeto de observar las diferencias y similitudes que existen entre los votantes de nuevos y viejos partidos políticos.

Palabras clave: partidos políticos tradicionales, nuevos partidos políticos, elecciones, cambio 


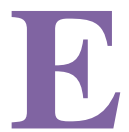

spaña lleva sumida en la inestabilidad desde el inicio efectivo de la crisis en 2008. Una inestabilidad, traducida en forma de crisis, que se ha manifestado en varias esferas de la vida del país: económica, política, institucional y social. Es verdad, que las instituciones españolas han estado anquilosadas desde su creación en la Transición, sin embargo, ha sido cuando ha estallado la burbuja inmobiliaria cuando se han destapado todas las ineficiencias institucionales de la política española que, además, se han visto deterioradas por los casos de corrupción (Sánchez-Cuenca, 2014). Es decir, los problemas que existen en el esqueleto institucional y político del país no han surgido de repente con la crisis, existen desde hace décadas, pero se han hecho más visibles y reconocibles para la población a partir de 2008, "pues una burbuja financiera no solo es un desastre económico, sino que también tiene un coste político considerable" (Galindo, Llaneras, Medina, San Miguel, Simón y Senserrich, 2015, 120). Todo ello ha generado que la sociedad española se haya convertido en una amalgama de ciudadanos que desconfían plenamente de sus instituciones. Las únicas instituciones que aprobaron la valoración de la sociedad española en 2015 fueron aquellas relacionadas con las fuerzas y cuerpos de seguridad del Estado (Guardia Civil, Fuerzas Armadas, policía) ${ }^{1}$. El resto de instituciones no superó la calificación de cinco (en una escala de 0 a 10), siendo los partidos políticos $(2,33)$, los sindicatos $(2,61)$ y el gobierno $(2,77)$, las instituciones peor valoradas $^{2}$. Esta desconfianza, como se señalaba antes, se ha disparado con los casos de corrupción y la mediatización de los mismos, pues la mayoría de la población en España cree que la gente que desconfía de los políticos lo hace debido a la corrupción (CIS, 2012; estudio 2930). Sin embargo, a esta corrupción se añade la respuesta política de los gobiernos en España ante la crisis, basada en medidas de austeridad, que no han conseguido mejorar la situación de la población en España, sino que han favorecido el aumento de las desigualdades sociales en el país, lo que ha dado lugar a la percepción, por parte de la ciudadanía, de la incapacidad de los gobiernos para dar respuesta a sus problemas cotidianos (Estefanía et al., 2015). De esta manera, la crisis, la desconfianza política y la incapacidad de los partidos políticos percibida por los ciudadanos, han generado un descontento social de la ciudadanía hacia los partidos políticos tradicionales (Laparra y Pérez Eransus, 2012), incluso, podría halarse de crisis de los partidos tradicionales. 


\section{Valero-Oteo - El Perfil del Votante del Cambio en España}

Todo lo anterior ha facilitado la aparición de nuevas formaciones políticas que abogan por un cambio en la forma de hacer política en España. Desde las elecciones al Parlamento Europeo de 2014 dos nuevos partidos políticos han irrumpido en la escena política española: Podemos y Ciudadanos (C's), si bien este último se hizo visible de forma más tardía, a partir de 2015. Estas formaciones han ido ganando progresivamente terreno a PP y PSOE, de manera que se puede hablar de la ruptura del bipartidismo tradicional en la historia de la democracia en España. Si en 2011 PP y PSOE se repartían el 84,5\% de los escaños del congreso (186 escaños el PP y 110 el PSOE) y el $73,39 \%$ de los votos (44,63\% el PP y $28,76 \%$ el PSOE) en 2015 la suma de los dos partidos ha descendido a un 60,8\% de los escaños y un $50,73 \%$ de los votos, pues las dos nuevas formaciones han absorbido un $31,1 \%$ de los escaños y un $34,59 \%$ de los votos ${ }^{3}$.

Este trabajo se centrará en analizar las características de los votantes de las nuevas formaciones políticas, es decir, de las personas que han escogido el cambio, en contra posición a los votantes de los partidos establecidos, los partidarios del inmovilismo. En este sentido, el trabajo quiere dar cuenta de las diferencias que existen entre los votantes de los nuevos y viejos partidos y las diferencias entre los votantes de las nuevas formaciones políticas.

\section{Metodología}

El estudio del comportamiento electoral es una rama consolidada de estudio que se mueve a caballo entre la Ciencia Política y la Sociología y que ha cobrado en los tiempos actuales de transformación una relevancia especial. El procedimiento más habitual para su estudio es el análisis de series bien de la intención, bien del recuerdo de voto ejercido en las distintas convocatorias electorales, tal como son recogidas en las encuestas pre- y post-electorales. Generalmente, esta intención o recuerdo de voto expresado por los entrevistados en la encuesta es objeto de reelaboración para mitigar el efecto distorsionador que la "opinión pública" ejerce sobre las respuestas demoscópicas, a través de diversos efectos como la "subida al carro ganador", que sobrestima a los ganadores de las elecciones (Cabrera, 2014) o el ocultamiento de las posiciones a priori minoritarias ("espiral del silencio" en la terminología de Noelle-Neumann, 2010) que generalmente se 
convierte en abstención ficticia. Esto es lo que se conoce como "cocina", de la que se ocupan los institutos de opinión con mayor o menor éxito predictivo, no exento en ocasiones de polémica. En cualquier caso, a pesar de algunos de los sesgos existentes, cabe destacar la utilidad que presentan los datos de este tipo de encuestas a la hora de predecir y explicar los cambios políticos que ocurren antes y después de los comicios electorales. Los mencionados datos de "cocina" son los que suelen llegar a la opinión pública y que pretenden reflejar de una manera lo más realista posible la distribución efectiva del voto en los comicios. Sin embargo, este "voto estimado", no es el objeto del presente trabajo, sino lo que en el argot técnico se conoce como "voto directo", esto es, las respuestas directamente obtenidas a las preguntas del cuestionario sin proceso estadístico posterior. De esta manera, a partir de los microdatos de las diferentes encuestas, se pueden explorar en profundidad los flujos entre las distintas opciones de voto tal cual son expresados por los entrevistados.

El objetivo de este trabajo es analizar el perfil ciudadano que ha decidido apostar por las nuevas fuerzas políticas, quienes han irrumpido en el panorama político dominante de los últimos dos años, esto es, Podemos y Ciudadanos. Para llevar a cabo esta tarea analítica se tomarán las series de datos de recuerdo "directo" de voto, construidas a partir de las encuestas post- electorales del Centro de Investigaciones Sociológicas (CIS), el más prestigioso centro de estudio de opinión pública del país. Estas encuestas suelen contar con unos requerimientos técnicos de alta calidad, lo que las sitúa como la fuente más reputada entre los estudiosos del comportamiento electoral.

Este trabajo se trata de una investigación empírico-descriptiva, en la que se compara el perfil de los votantes de los nuevos partidos (Podemos y C's) con el de los partidos hegemónicos españoles, PP y PSOE, a la vez que se comparan los perfiles de cada uno de los nuevos partidos. De esta manera, se extrae la información necesaria para evidenciar que el electorado de Podemos y C's se diferencia de los votantes de los partidos tradicionales y que, a su vez, existen diferencias entre los votantes de ambos partidos. Es decir, lo que se pretende es averiguar si existen (y si es así, cuáles son) características específicas entre los votantes del cambio, que dan lugar a la creación de un perfil específico, cuando se las compara con las de los 


\section{Valero-Oteo - El Perfil del Votante del Cambio en España}

partidos tradicionales que han protagonizado el escenario político en las últimas décadas. Además, se trata de averiguar si dentro de su igualdad, en contraposición a PP y PSOE, existen diferencias entre los votantes de C's y Podemos.

Lo que se pretende investigar es la incidencia que tienen ciertos factores sociales e individuales sobre el voto a Podemos y a Ciudadanos. Para ello, se van a calcular porcentajes de columna ${ }^{4}$ mediante tablas de contingencia, obtenidas a través de cruces entre una variable dependiente, relacionada con el recuerdo de voto con variables de tipo sociodemográfico, sociopolítico y socioeconómico.

- Recuerdo de voto: “¿Podría decirme a qué partido o coalición votó en las pasadas elecciones?

Asimismo, como variables independientes se han escogido varias de las preguntas de los cuestionarios que aportan una valiosa información a la hora de votar a los nuevos y viejos partidos:

1. Variables sociodemográficas: nivel de estudios, edad, tamaño de municipio y estatus socioeconómico.

2. Variables políticas: autoubicación ideológica, valoración sobre la situación política de España, recuerdo de voto en las elecciones de 2011, participación política e interés en la campaña electoral.

3. Variables económicas: valoración de la situación económica personal, ingresos económicos mensuales y situación laboral.

El método de análisis predominante en el estudio del perfil del votante del cambio va a ser la tabla de contingencia. Las tablas de contingencia sirven para estudiar, inicialmente, la asociación entre variables y, por extensión, el efecto (mediante la dependencia de valores) de una o varias variables sobre otra y son, posiblemente, el método estadístico más ampliamente utilizado, al menos en estudios de corte sociológico (Escobar Mercado, Fernández Macías y Bernardi, 2010, 231-232).

En definitiva a través de la elaboración de tablas de contingencia se pretende obtener resultados que permitan establecer cuáles son las características (variables) que marcan la diferencia entre los electores de los 
nuevos y los viejos partidos, así como las características (si existieran) que diferencian a los votantes de Podemos y C's.

\section{El Perfil del Votante del Cambio}

\section{Perfil Sociodemográfico}

En este apartado el objetivo es averiguar cuáles son las características sociodemográficas de la población que diferencian a unos votantes de otros, además de comparar la evolución del perfil sociodemográfico de los votantes desde las elecciones al PE, concretamente, el de los votantes de las nuevas fuerzas políticas.

De acuerdo con el tamaño de municipio en el que residen los votantes (Tabla 1, anexos) en las zonas rurales (menores o iguales a 10.000 habitantes) la presencia de los partidos tradicionales es mucho más acusada, el $38,6 \%$ y el $35,9 \%$ de los votantes que viven en zonas rurales manifestaron su voto a PP y PSOE, respectivamente, en las elecciones del 20 de diciembre de 2015 , frente a un $12,4 \%$ y un $13,1 \%$, a C's y Podemos. De la misma manera, los mayores porcentajes de voto entre los electores de estos dos últimos partidos, se encuentran entre la población de las zonas más pobladas, es decir, municipios superiores a los 100.000 habitantes. Esto refleja el carácter más urbanita de los votantes tanto de Podemos, como de C's. Esto no quiere decir que en las zonas rurales no se vote a los nuevos partidos y en las zonas urbanas no se vote a los tradicionales, los votos se reparten por toda la geografía de España; pero sí quiere decir que en el mundo rural se tiende a votar más a las dos grandes coaliciones tradicionales con respecto a las zonas más pobladas. Si tenemos en cuenta los intensos desequilibrios representativos de la ley electoral (d'Hondt), que favorece a los territorios menos poblados y más rurales (Lago, 1999), potenciando el voto a los partidos tradicionales; destaca, aún más, el éxito en la consecución de escaños por parte de C's y Podemos, quienes han logrado lo que otros partidos minoritarios no habían conseguido hasta ahora: lograr un amplio número de escaños partiendo de una clara situación de desventaja electoral.

En comparación con los datos de las elecciones europeas de 2014, el resultado es el mismo. Los votantes de las dos fuerzas mayoritarias fueron 


\section{Valero-Oteo - El Perfil del Votante del Cambio en España}

más numerosos en el mundo rural, mientras que la mayoría de los votantes de los nuevos partidos se encontraban en las grades zonas urbanas. Cabe destacar los bajos porcentajes de voto a C's que aparecen en esta gráfica (fenómeno que se repetirá en las posteriores tablas referidas a las pasadas elecciones europeas), lo que se debe al menor conocimiento de dicho partido en ese período, pues, como se señalaba anteriormente, su presencia mediática ha sido más acusada a partir del año 2015.

La edad suele ser un factor decisivo a la hora de votar a un partido u otro, puesto que los jóvenes son actores con mayor propensión al cambio electoral y los mayores son los que presentan mayor aversión al cambio y a los riesgos que dicho cambio pueda entrañar (González y Caínzos, 2012). En este sentido, cuanto mayor sea el cambio que se pueda dar en el juego electoral, mayor es el papel que se adjudica a los jóvenes en el mismo (Salido y Martín, 2007). Así pues, en este análisis se aprecia cómo la edad influye en la tendencia de voto a cada uno de los partidos. En la Figura 1 se observa cómo va aumentando el voto a PP y PSOE conforme va aumentando la edad de los encuestados. Si bien la tabla muestra cómo el PP es un partido más envejecido que el PSOE, pues más de la mitad de los votantes (un $54,3 \%$ ) mayores de 65 recuerdan haber votado al PP en las elecciones del 20D, mientras que el PSOE reparte más sus votos entre los mayores de 65 $(32,2 \%)$ y las personas de entre 50 y 64 años $(37,8 \%)$. Entre las dos nuevas fuerzas políticas ocurre justamente lo contrario: a medida que disminuye la edad de los votantes aumenta el porcentaje de recuerdo de voto a estos dos partidos. De esta manera, el 59,4\% de los votantes que se encontraban en la franja de edad entre los 18 y los 36 años, manifestaron haber votado a Podemos o C's en las generales de 2015. Bien es verdad, que Podemos se muestra como el partido preferido de los más jóvenes, pues el porcentaje más alto del voto de los jóvenes fue a Podemos con un 32,7\%. Por su parte, C's es, también, un partido marcadamente joven pero reparte sus votos, de manera más equitativa que Podemos, entre los votantes de 18 a 36 años $(26,7 \%)$ y de 37 a 49 años $(25,5 \%)$. 


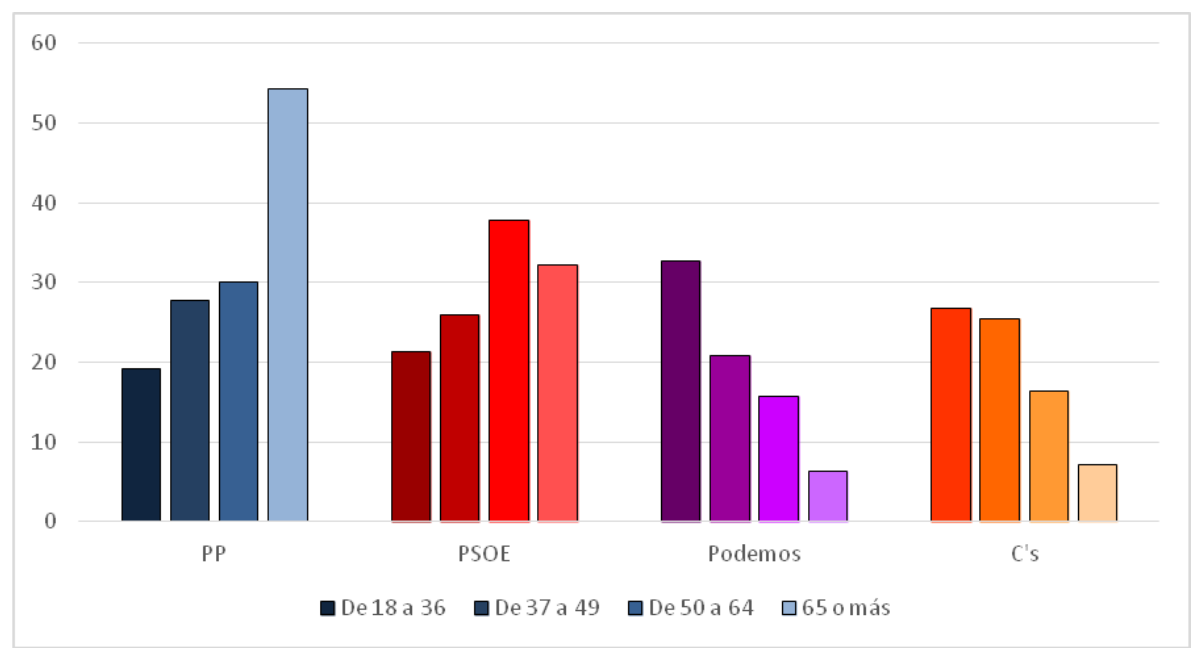

Figura 1. Intención de voto*Edad (2016)

Fuente: Elaboración propia a partir de los datos del CIS. Estudio no 3126

En cuanto a las elecciones al PE de 2014, los datos son similares. Los partidos tradicionales eran, después de las elecciones europeas, los partidos más envejecidos, igual que ahora. Sin embargo, en cuanto a los dos nuevos partidos, Podemos se mostraba en 2014 más joven que a finales de 2015, al revés que C's, que en 2014 tenía un porcentaje de votos en la franja de edad de 37 a 49 años mucho mayor que en el resto de intervalos de edad.

Si se compara la edad media del voto a los partidos en los dos períodos las diferencias se observan con mayor claridad (Figura 2). Lo más destacable es la disminución en la edad media de voto a C's, de 47,74 años en 2014 a 43,66 años en 2015, lo que quiere decir que en año y medio este partido ha sido capaz de atraer el voto de muchos jóvenes a su partido. Por el contrario Podemos, ha envejecido desde las europeas, aunque de forma menos acusada con un año de variación en la media, lo que significa que ha ampliado su abanico de votantes a gente más mayor. 


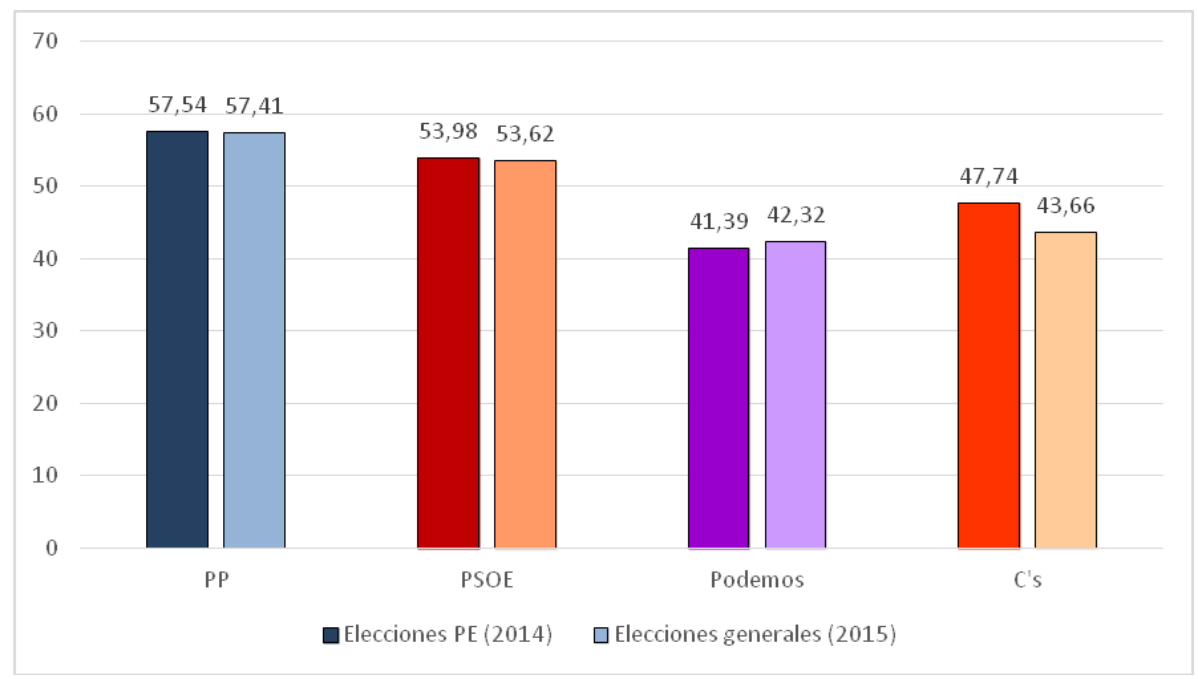

Figura 2. Evolución de la edad media de voto a los partidos.

Fuente: Elaboración propia a partir de los datos del CIS. Estudios 3028, 3126.

El nivel de estudios de la población, también influye marcadamente en el voto a un partido u otro. Los partidos tradicionales presentan una mayoría de votantes con niveles de estudios primarios o inferiores, tanto es así que el $85 \%$ de los votantes con estos niveles de estudios manifestaron haber votado al PP $(43,1 \%)$ o al PSOE $(41,9 \%)$ en las pasadas elecciones de diciembre (Tabla 2, anexos). Por el contrario Podemos y C's presentan un perfil de votante mayoritario con estudios superiores. Los votantes de los nuevos partidos se caracterizan, pues, por poseer un perfil con un nivel de estudios superior al de los votantes de los partidos tradicionales. Sin embargo, cabe mencionar que dentro del perfil de los nuevos partidos, C's es el que presenta más votantes con estudios universitarios, un $28,7 \%$, frente a Podemos con un $25,7 \%$.

En comparación con las elecciones al PE, el panorama ha cambiado ligeramente. En las elecciones europeas de 2014 los partidos que tenían mayor porcentaje de votantes con estudios universitarios eran PP y C's, frente al PSOE, donde predominaban los votantes con estudios primarios o menos y Podemos, con un perfil mayoritario de votante con niveles de 
estudios secundarios, aunque el número de universitarios también era considerable.

Para finalizar el perfil sociodemográfico del votante del cambio, hay que destacar la importancia de la variable estatus socioeconómico ${ }^{5}$ a la hora de elegir la papeleta del voto. En este caso concreto, los perfiles de los votantes de PP y PSOE se separan y dejan de converger como lo hacían respecto a las variables anteriores. El PSOE encuentra a sus mayores votantes entre los obreros (cualificados y no cualificados), mientras que el PP lo hace entre las viejas clases medias, pues casi la mitad de las personas que pertenecen a dicho grupo (49,3\%), manifestó haber votado al PP (Figura 3). Por su parte, Podemos presenta un perfil mayoritario de votantes de clase alta/media alta, al igual que C's quien también presenta altas cotas de voto en este grupo, aunque su perfil mayoritario es de nuevas clases medias.

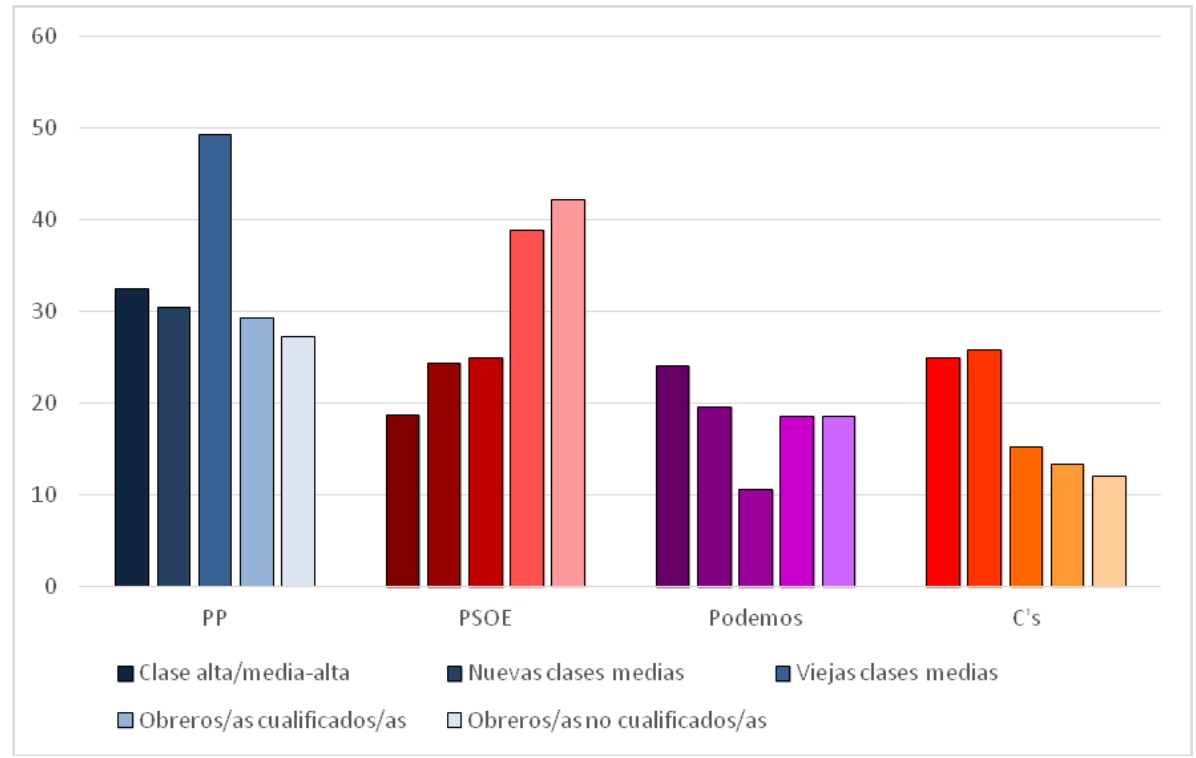

Figura 3. Recuerdo de voto (2015)*Estatus socioeconómico (2016)

Fuente: Elaboración propia a partir de los datos del CIS. Estudio n ${ }^{\circ} 3126$

En relación a las elecciones europeas de 2014, los resultados de los perfiles de voto son similares. Los datos más destacables son el mayor 


\section{Valero-Oteo - El Perfil del Votante del Cambio en España}

número de votantes de las nuevas clases medias en Podemos, que superaban a la clase alta y media alta en 2014, al contrario que en C's, donde para 2014 predominaba esta última clase, por encima de las nuevas clases medias.

Hasta ahora se han podido comprobar numerosas diferencias entre los votantes de los denominados viejos y nuevos partidos políticos. Sin embargo las diferencias entre los votantes de estos dos nuevos partidos son mínimas, por lo tanto, el perfil sociodemográfico del cambio está bastante unificado. En las siguientes páginas comprobaremos si las similitudes entre los votantes de estos nuevos partidos también existen en el plano político y económico.

\section{Perfil Sociopolítico}

En primer lugar es interesante analizar cuál es el perfil ideológico de los votantes de cada uno de los partidos y es en este punto donde quizá se encuentren las mayores diferencias entre los dos nuevos partidos. La autoubicación ideológica de los electores, marca un claro sesgo a la hora de votar a cada uno de los cuatro partidos mayoritarios (Tabla 3, anexos). El PP es el partido político por el que se decanta la mayor parte de los votantes con un perfil de ideología de extrema derecha, derecha y, en menor medida, de centro. C's, por su parte, ha sido elegido como el partido favorito de los electores del centro del espectro ideológico, ganándole terreno en este sector al Partido Popular, aunque una pequeña parte $(13,2 \%)$ de los electores que se autodefinen de derechas, manifestó también haber votado a Ciudadanos. Al otro lado del eje, en la izquierda política, se ubican los electores de Podemos y PSOE. El primero, es el partido elegido, sobre todo, por las personas que se definen como partidarias de la extrema izquierda $(58,1 \%)$, mientras que el PSOE estaría más concentrado en una izquierda más moderada $(59,2 \%)$.

En relación a las elecciones europeas se puede señalar que los resultados son parecidos. Podemos mantiene su carácter ideológico desde 2014, aunque en 2015 se ha radicalizado ligeramente. Por su parte, C's ha ido ganando terreno tanto en el centro del espectro ideológico, como se señalaba anteriormente, como a la izquierda y, sobre todo, a la derecha del mismo, pero siempre en el sector moderado. Comparando la media ideológica de los partidos ${ }^{6}$, para cada período, se ve de manera más resumida lo expuesto anteriormente (Tabla 1). 
Tabla 1

Comparación de la media ideológica de los partidos

\begin{tabular}{lll}
\hline & 2014 & 2015 \\
\hline PP & 7,04 & 6,95 \\
PSOE & 3,72 & 3,68 \\
Podemos & 3,29 & 3,15 \\
C's & 5,07 & 5,47 \\
\hline
\end{tabular}

Fuente: Elaboración propia a partir de los datos del CIS. Estudios n $3028, n^{\circ} 3126$.

Una vez visto el perfil ideológico de los votantes de los nuevos y viejos partidos, es interesante analizar a qué partidos votaron con anterioridad (en las elecciones de 2011) los nuevos votantes de Podemos y C's, es decir, a qué partidos han "robado" los votos las nuevas formaciones políticas. De esta manera, la Figura 4 muestra cómo casi el $60 \%$ de los votos de Podemos en 2015 proceden de los partidos PSOE e IU y en el caso de C's, de PP y PSOE. De esta manera se corrobora, con los análisis anteriores, que Podemos ha arrastrado a sus filas a los votantes de izquierda y extrema izquierda y C's a los de centro derecha y, en menor medida, centro izquierda. Sin embargo, ambos partidos presentan un alto porcentaje de personas que no votaron, votaron nulo, en blanco, no contestaron o no recuerdan a quien votaron en 2011 (28\% en Podemos y 26,7\% en C's).

La situación en 2014 era algo diferente. En el caso de Podemos éste partido era más variopinto, recogía mayor porcentaje de voto a partidos como PP o UPyD o a otros partidos, aunque predominaba el voto a PSOE e IU (64,4\%), en mayor medida que en 2015 (Figura 5). De la misma manera, el porcentaje de voto nulo, en blanco, abstención, no sabe o no recuerda, era mucho menor en 2014 que en 2015 (13,1\% frente a 28\%). C's, por su parte, ha cambiado su estructura de voto. Desde las europeas, C's ha absorbido a un amplio número de votantes de PP y PSOE: en 2014 los porcentajes eran de $34,4 \%$ y $9,4 \%$, respectivamente; mientras que en 2015 éstos se han convertido en un $41,4 \%$ y un $19,1 \%$. Esto corrobora que C's se ha hecho hueco tanto en el centro del espectro político, como a la derecha y a la izquierda del mismo, como se señalaba anteriormente. Por otro lado, en 2014 el 53,8\% de los votantes de C's, votaron en 2011 a "otros partidos" o había 
votado blanco, nulo, no se acordaban o no contestaron. Lo que se puede extraer de esta comparación del trasvase de votos a Podemos y C's entre los años 2014 y 2015 , en relación al voto en las elecciones de 2011, es que los nuevos partidos, han atraído a un gran número de votantes de los partidos más relevantes y que en las elecciones de diciembre, atrajeron el voto de personas que anteriormente habían decido votar en blanco o nulo, ya fuera por una actitud de duda frente al voto, desinterés, indiferencia o descontento con el abanico de partidos que se ofrecía en el año 2011.

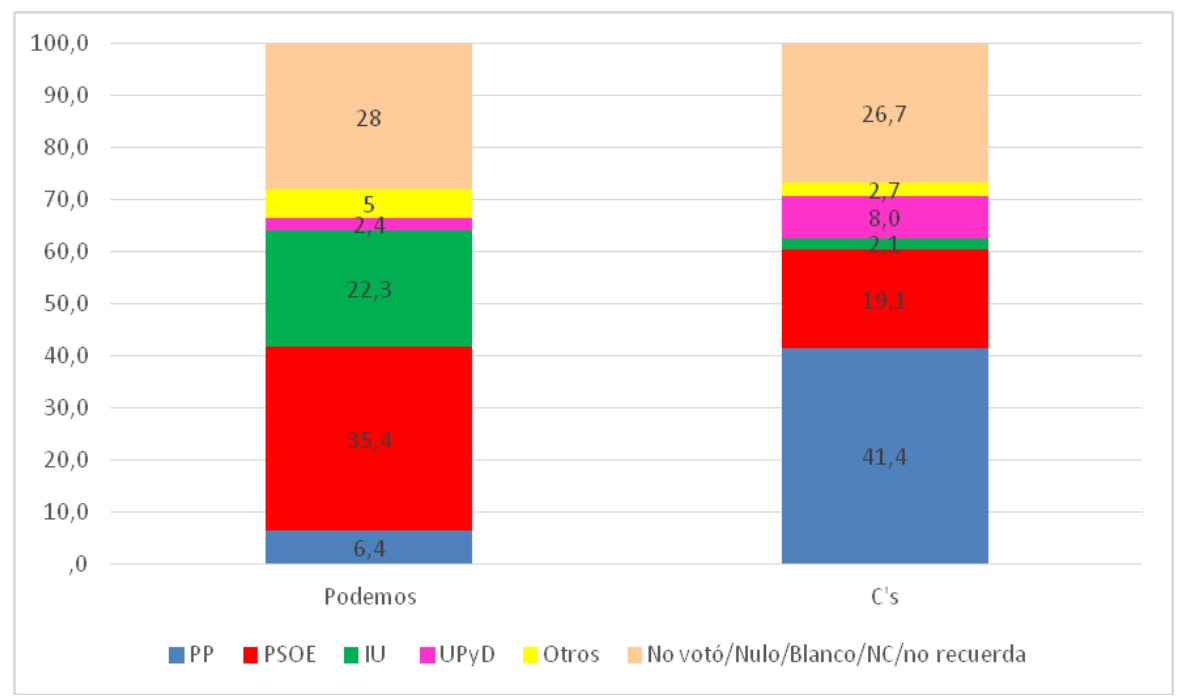

Figura 4: Recuerdo de voto en las elecciones de 2011 (2015)

Fuente: Elaboración propia a partir de los datos del CIS. Estudio 3126 


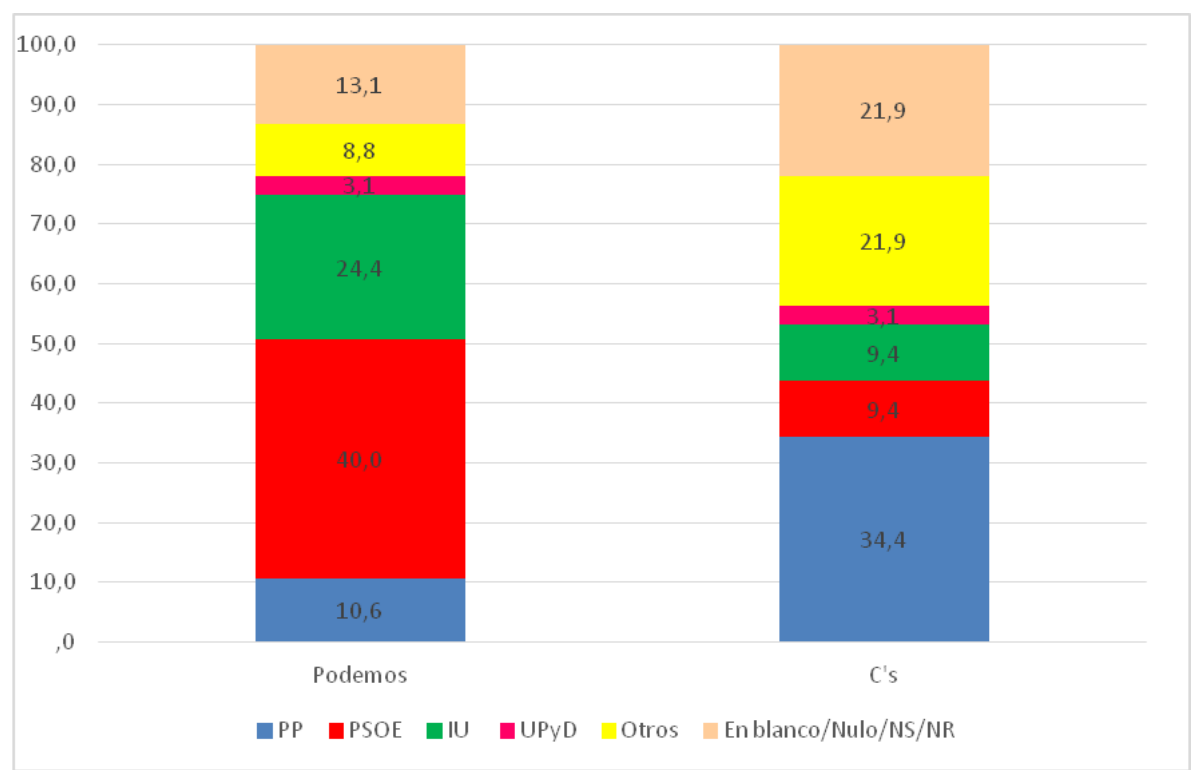

Figura 5: Recuerdo de voto en las elecciones de 2011 (2014)

Fuente: Elaboración propia a partir de los datos del CIS. Estudio no 3028.

Las siguientes variables a analizar en este apartado están relacionadas con las actitudes de los votantes hacia la política, concretamente, se van a analizar variables como el grado de interés con el que los votantes han seguido la campaña electoral, la valoración que hacen de la situación política del país y el tipo de participación política en la que más se implican los votantes de los diferentes partidos. El primer análisis consiste en observar si el interés con el que los votantes siguieron la campaña electoral del 20D está relacionado con el voto a los partidos. Los nuevos partidos presentan un perfil mayoritario de votantes que han seguido la campaña electoral con mucho interés, en especial Podemos. Por el contrario, tanto PP como PSOE, se caracterizan por tener un perfil de votante muy poco interesado en el transcurso de la campaña electoral, sobre todo, dentro del partido del PSOE, pues el 75,1\% de los/as encuestados/as que siguieron la campaña con ningún interés, manifestó haber votado a los dos partidos tradicionales (Tabla 4, anexos). 
En cuanto a la valoración acerca de la situación política por la que pasa el país, a excepción del PP, quien presenta una mayoría de votantes que califican la situación de manera positiva, el resto de partidos presenta un perfil de voto crítico con la situación política, valorándola como mala o muy mala.

Tabla 2

Participación política de los votantes de los diferentes partidos

\begin{tabular}{|c|c|c|c|c|c|}
\hline Frecuencia & $\begin{array}{l}\text { Asistir a una } \\
\text { manifestación }\end{array}$ & $\begin{array}{l}\text { Boicot a } \\
\text { productos }\end{array}$ & $\begin{array}{l}\text { Participar en } \\
\text { una huelga }\end{array}$ & $\begin{array}{c}\text { Ocupar/ } \\
\text { encierros/ } \\
\text { bloqueo tráfico }\end{array}$ & $\begin{array}{c}\text { Participar en sitios } \\
\text { de discusión } \\
\text { política }\end{array}$ \\
\hline \multicolumn{6}{|l|}{ PP } \\
\hline Bastante & 3,9 & 6,9 & 2,4 & 0 & 0,7 \\
\hline Alguna & 28,3 & 23,3 & 20 & 1,7 & 4 \\
\hline \multicolumn{6}{|l|}{ vez } \\
\hline Nunca & 67,8 & 69,8 & 77,6 & 98,3 & 95,4 \\
\hline \multicolumn{6}{|l|}{ PSOE } \\
\hline Bastante & 9,4 & 15 & 5,8 & 0,6 & 1,5 \\
\hline Alguna & 37,1 & 25,9 & 35,2 & 3,6 & 4,7 \\
\hline \multicolumn{6}{|l|}{ vez } \\
\hline Nunca & 53,4 & 69,1 & 59 & 95,8 & 93,8 \\
\hline \multicolumn{6}{|l|}{ Podemos } \\
\hline Bastante & 23,8 & 18,9 & 18,1 & 1,1 & 9,2 \\
\hline Alguna & 46,6 & 39,1 & 45,5 & 12,5 & 15 \\
\hline \multicolumn{6}{|l|}{ vez } \\
\hline Nunca & 29,5 & 42 & 36,4 & 86,4 & 75,8 \\
\hline \multicolumn{6}{|l|}{ C's } \\
\hline Bastante & 8,3 & 12,7 & 4,7 & 0,1 & 2,4 \\
\hline Alguna & 44 & 34,1 & 39,4 & 3,4 & 7,3 \\
\hline \multicolumn{6}{|l|}{ vez } \\
\hline Nunca & 47,4 & 53,2 & 55,8 & 96,4 & 90,3 \\
\hline
\end{tabular}

Fuente: Elaboración propia a partir de los datos del CIS. Estudio nº3126 
La última variable del perfil sociodemográfico es la participación política en diferentes actividades más allá de la participación electoral. La Tabla 2 muestra la frecuencia con la que los votantes de los diferentes partidos se implican en actividades como asistir a una huelga autorizada, hacer boicot a productos por diversas razones (económicas, políticas, ecológicas...), participar en una huelga, ocupar edificios, participar en encierros o bloquear el tráfico y, por último, participar en sitios de discusión política por internet. Los datos de la tabla arrojan que las actividades en las que más participan los votantes (de todos los partidos) son la asistencia a manifestaciones y la participación en huelgas, mientras que las actividades en las que menos se implican son la ocupación, los encierros y el bloqueo del tráfico y la discusión política a través de internet. Amén de dichos datos, los votantes que más participan en cualquiera de estas actividades son los de Podemos, seguidos por el PSOE en lo que a manifestaciones y huelgas se refiere y de C's en actividades como el boicot a productos y el debate político en internet. Por su parte, el PP es el partido con menores cotas de participación entre sus votantes.

\section{Perfil Socioeconómico}

El último de los perfiles a analizar es el socioeconómico. La esfera económica siempre ha estado muy relacionada con la esfera política. En general, se suele pensar que las personas con mayores ingresos y puestos de trabajo más profesionales o mejor valorados suelen acercarse más a la derecha política, mientras que las personas con menores ingresos y puestos de trabajo menos cualificados se decantan por la izquierda. El primer análisis de este apartado da cuenta de la relación que existe entre los ingresos mensuales de los votantes y su propensión a votar a cada una de las cuatro fuerzas políticas.

La Figura 6 refleja, precisamente, cómo el nivel de ingresos de los electores influye en su tendencia de voto. Entre los partidos tradicionales, el $\mathrm{PP}$ es un partido que recoge, en su mayoría, votantes con un nivel mensual de ingresos de entre $600 €$ y $1200 €$ y el PSOE recoge una mayoría de ciudadanos cuyos ingresos se encuentran en el umbral de 600-900€. Podemos y C's, por otro lado, poseen un perfil de voto con un alto nivel de 


\section{Valero-Oteo - El Perfil del Votante del Cambio en España}

ingresos. C's reparte sus votos, sobre todo, entre personas con ingresos entre $1200 €$ y $1800 € \mathrm{y}$, en menor medida, de personas con ingresos superiores a $1800 €$. Podemos, por su parte, presenta una mayoría de votantes con un nivel de ingresos superior a los $1800 €$, aunque cabe destacar, que a este perfil de ingresos le sigue el de votantes con ingresos menores a $600 €$, por lo que tiene un perfil bastante polarizado. Esta variable se relaciona directamente con la de estatus socioeconómico. De esta manera, si el perfil socioeconómico mayoritario, por ejemplo, de Podemos es de personas de clase alta/media alta, es lógico que el nivel de ingresos predominante sea alto, al igual que si en el PSOE predominan los votantes de clase obrera, su perfil de ingresos mayoritario será menor.

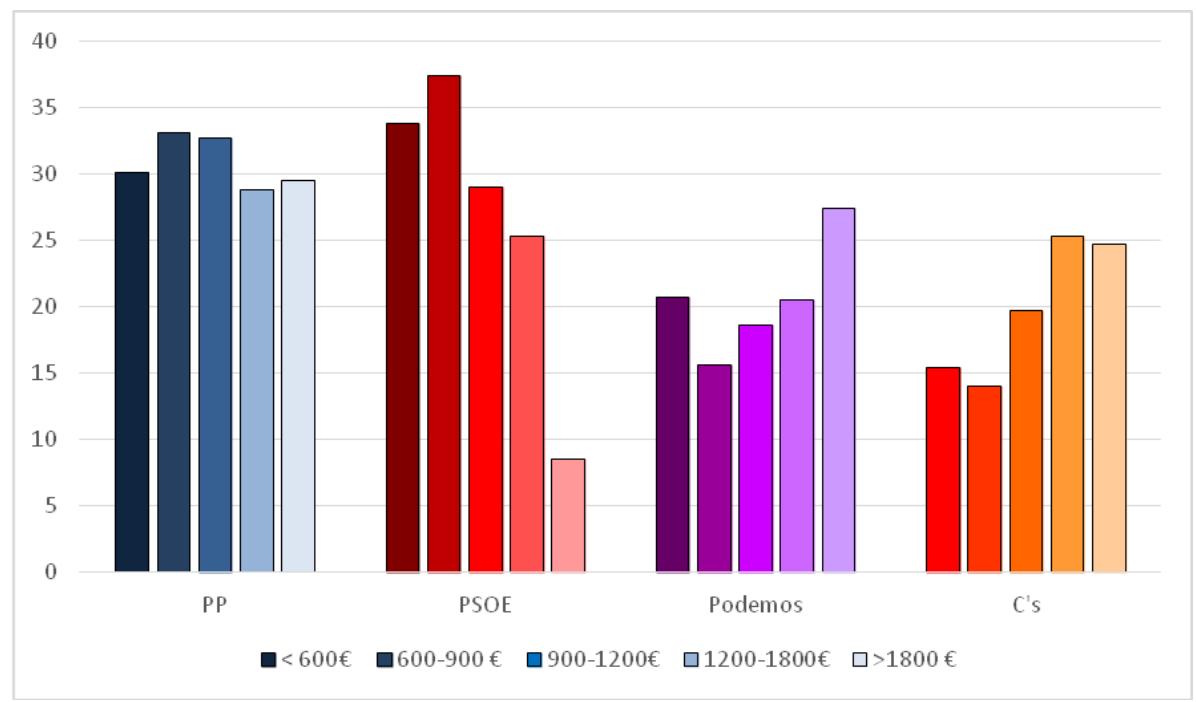

Figura 6: Recuerdo de voto (2015)*Ingresos

Fuente: Elaboración propia a partir de los datos del CIS. Estudio no 3124

En el caso de las elecciones europeas (Tabla 5, anexos), en 2014 el voto socialista estaba más precarizado; PP y C's mantenían un perfil similar al actual y Podemos presentaba un perfil de votante con menores ingresos (1200-1800€). Con esto se puede decir que la única variación importante, 
entre los nuevos partidos, ha sido el aumento en el nivel de ingresos del perfil del electorado de Podemos.

El segundo factor socioeconómico que se ha seleccionado en este trabajo es la valoración sobre la situación económica personal de los encuestados. Los partidos que albergan los votantes más conformes con su situación económica personal son el PP y C's, mientras que en las filas del PSOE y Podemos los votantes se caracterizan por calificar su situación como mala o muy mala. Con respecto a 2014 y a las elecciones europeas (Tabla 6, anexos) lo más destacable es que en 2014 el 50\% de las personas que se definían con una buena situación económica eran votantes de Podemos y, a su vez, éstas conformaban el grueso mayoritario de votantes del partido. C's, por su parte, se ha mantenido similar, con votantes con una buena situación económica personal.

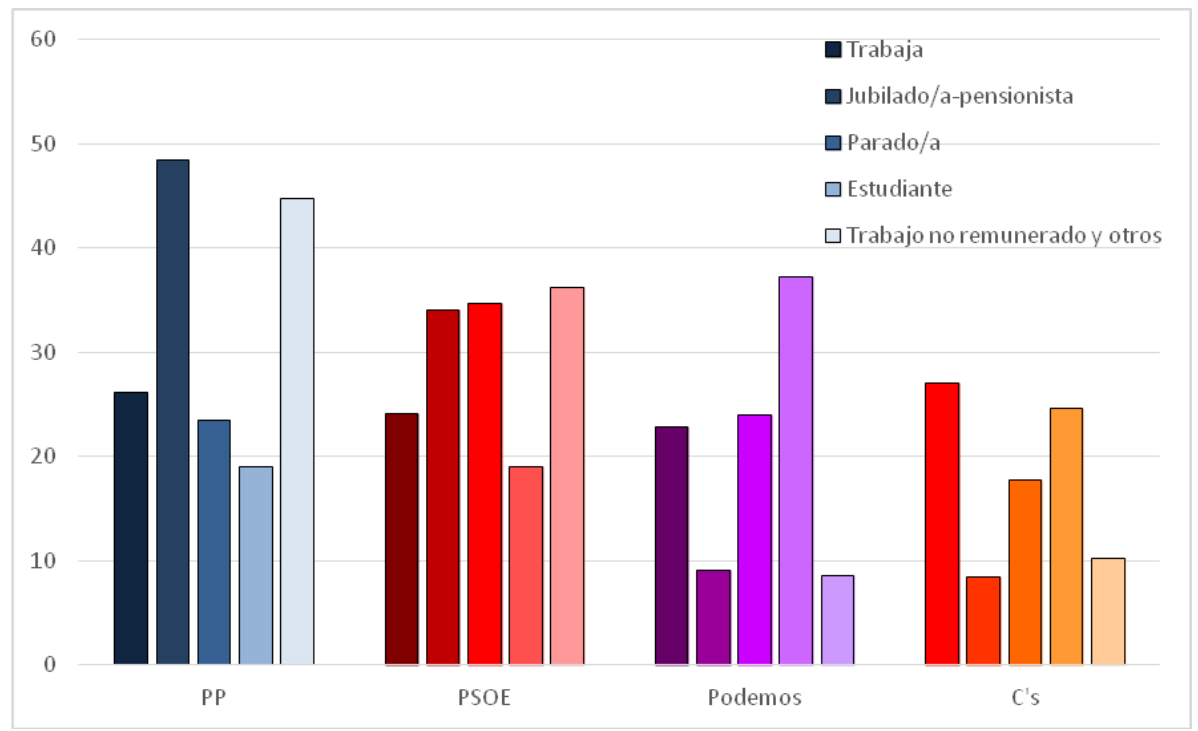

Figura 7: Recuerdo de voto (2015)*Situación laboral

Fuente: Elaboración propia a partir de los datos del CIS. Estudio n 3126.

La última de las variables analizadas es la situación laboral. En este caso lo que se busca es comprobar si existe una relación directa, entre la situación laboral y el voto, que permita conformar un tipo de perfil específico para 


\section{Valero-Oteo - El Perfil del Votante del Cambio en España}

cada partido. La Figura 7 lo corrobora. El PP en la actualidad es un partido formado sobre todo por pensionistas y jubilados, al igual que el PSOE, aunque este último incorpora también al grupo de los parados/as. Podemos es un partido compuesto en su mayoría por estudiantes (el 37,3\% de los encuestados estudiantes, manifestó haber votado a este partido en 2015) seguido por el grupo de los/as parados/as. Por último, C's posee un perfil mayoritario de trabajadores. Esta división de perfiles está muy relacionada con la variable edad. Si PP y PSOE son partidos muy envejecidos, lógicamente en sus filas tendrán un perfil mayoritario de jubilado/a, o de personas que se han quedado en paro a una edad adulta avanzada (como puede ser el caso del PSOE), mientras que los partidos más jóvenes estarán compuestos por personas en edad de trabajar y por estudiantes. Si se comparan estos resultados con los resultados de la encuesta postelectoral de las elecciones europeas, se observa cómo los perfiles de voto de los nuevos partidos apenas han variado.

\section{Últimas Consideraciones}

Se han elaborado ya diversos análisis relacionados con los resultados de las elecciones del 20D, como es el caso del CIS, o de las características de los votantes de los distintos partidos, como lo hizo Javier Elzo ${ }^{7}$ antes de las elecciones del 26J, en este trabajo se ha pretendido, además de eso, comparar los resultados del voto a las cuatro formaciones mayoritarias (haciendo hincapié en las neófitas) desde las elecciones al Parlamento Europeo. El principal problema de esta comparación es la diferencia entre la "importancia" unas elecciones europeas ("segundo orden") y unas generales ("primer orden") para la ciudadanía, pues en las europeas se considera que hay menos aspectos en juego que en los comicios de carácter nacional (Reif y Schmitt, 1980). Por otro lado, existe una gran diferencia de participación electoral entre unos comicios y otros, pues cuanto más complejo es el entramado político de un sistema electoral, más coste le supone al votante acudir a las urnas (Gallego, 2011). Finalmente, en unas elecciones europeas la intención con la que se emite el voto es distinta a la de unas elecciones generales. En este sentido, en unos comicios de segundo orden, el carácter del voto es más expresivo que instrumental, pues al existir menos aspectos 
en juego los electores pueden manifestar su voto de manera diferente, desde votar a partidos con mayor cercanía ideológica a la suya, quienes no gozarían de tantas posibilidades en una competición nacional (Belluci et al, 2012); hasta utilizar el voto europeo como voto de castigo hacia el gobierno nacional vigente en el momento de los comicios, como pudo ocurrir en las Elecciones al Parlamento Europeo de 2014. Por todo ello, es más complejo realizar una comparación entre los resultados electorales de comicios de distinto orden, sin embargo, para comparar los inicios de los partidos era necesario utilizar los resultados europeos. Quizá podrían haberse comparado los resultados de las elecciones del 20D y el 26J, sin embargo, los datos postelectorales de las elecciones de junio aún no han sido publicados $y$ después de los errores de medición de la encuesta preelectoral, no hubiera resultado un análisis "real" del voto a los partidos.

Dejando a un lado lo anterior, este trabajo es interesante para analizar cómo eran los votantes de las distintas fuerzas en 2014 y cómo han ido transformándose hasta el año 2015, pues no hay que olvidar que Podemos nació escasos meses antes de los comicios europeos y C's era un partido, hasta entonces, desconocido en un nivel nacional y fue después de dichas elecciones cuando comenzaron a hacerse visibles y conocidos por toda la ciudadanía.

\section{Conclusiones}

Con todos los análisis anteriores se confirma que existen características que definen a los nuevos partidos en contraposición a los partidos tradicionales. Las características que marcan esa barrera entre el voto de nuevos y viejos partidos son, sobre todo, de carácter sociodemográfico. Los primeros tienen más presencia entre los jóvenes urbanitas, con altos niveles de estudios y perteneciente a las nuevas clases medias o la clase media y media/alta; además de estar más presentes entre los votantes más interesados en política, críticos con la situación política del país y con mayor participación política más allá de las urnas, sobre todo en el caso de Podemos que es el partido con los votantes más participativos. Los partidos tradicionales, por el contrario, tienen una influencia más acusada entre los votantes del mundo rural, de edades más avanzadas (mayores de 50 años), con un nivel de estudios 


\section{Valero-Oteo - El Perfil del Votante del Cambio en España}

bastante inferior y con mucho menos interés político. En cuanto al factor clase social, PP y PSOE se distancian, el PP tiene más peso, sobre todo, entre las viejas clases medias y el PSOE entre la clase obrera; lo mismo ocurre con la valoración política del país, los que mejor la valoran tienden a votar al PP, mientras que el PSOE tiene un perfil de votante más crítico con la situación política.

En relación a la ideología y los factores socioeconómicos los perfiles de Podemos y C's dejan de converger. Quizá sea el perfil ideológico el que más distancia a los votantes de estos dos partidos. Podemos se ha convertido en un partido cuyo votante más representativo es de extrema izquierda e izquierda, mientras que C's es un partido compuesto por votantes del centro y la derecha del espectro político. Es decir, en términos ideológicos Podemos está más cerca del PSOE y C's del PP, tanto es así que se puede hablar de nueva izquierda y nueva derecha en España, nuevas ideologías que han absorbido a un importante número de votantes de los partidos tradicionales. Lo mismo ocurre a la hora de valorar la situación económica personal, los votantes de Podemos valoran su situación de manera muy negativa mientras que en C's ocurre lo opuesto. Bien es verdad que, respecto al nivel de ingresos, los dos partidos presentan un perfil de votante que supera los $1200 €$, aunque Podemos posee un perfil mayoritario con ingresos mensuales superiores al perfil de C's. Por último, Podemos tiene un perfil mayoritario de estudiantes y C's de personas que trabajan. Es este sentido, C's representaría a la población joven pero, sobre todo, de mediana edad, con alto nivel de estudios y una situación laboral y económica buena o muy buena, mientras que Podemos representaría a los jóvenes con alto nivel de estudios y con un poder adquisitivo bastante alto. Por lo tanto, sí que existen diferencias entre el perfil del voto del cambio y el perfil de voto tradicional, cuyo elemento de divergencia es la ideología.

Para terminar, cabe destacar que, en relación a las elecciones al Parlamento Europeo, los perfiles de voto de los dos nuevos partidos apenas han sufrido cambios. En lo que a edad se refiere dentro de Podemos se ha producido un aumento en la edad media de su votantes (de un año), al contrario que en C's, en el que se ha producido una disminución de la misma (de cuatro años) desde 2014 hasta 2015. Otro cambio que puede destacarse se relaciona con la autoubicación ideológica de los votantes. En el caso de 
Podemos, sus votantes han radicalizado su ideología desde 2014, aunque de forma muy leve, por otro lado, los de C's se han acercado más a la derecha ideológica, cambio más acusado que en el caso de Podemos. A pesar de ello las diferencias, como ya se ha dicho, son muy leves entre estos dos años para ambos partidos, es decir, sus perfiles de voto apenas han variado desde el debut de las formaciones en las elecciones europeas.

\section{Notas}

${ }^{1}$ Datos del CIS. Barómetro de abril 2015. Estudio n 3080

${ }^{2}$ Datos del CIS. Barómetro de abril 2015. Estudio n 3080

${ }^{3}$ Datos del Ministerio del Interior, http://resultadosgenerales2015.interior.es/congreso/\#/ES201512-CON-ES/ES

${ }^{4}$ En este trabajo se ha utilizado únicamente el porcentaje de columna, debido a la "regla de Zeisel" que se aplica "siempre que uno de los dos factores del cuadro dimensional pueda considerarse como causa de la distribución del otro factor. La regla es que los porcentajes deben computarse en el sentido del factor causal (Zeisel, 1962, 37).

${ }^{5}$ El CIS clasifica la categoría de estatus socioeconómico en los siguientes valores: clase alta/media alta (profesionales y técnicos/as, directivos/as y cuadros medios), nuevas clases medias (asalariados no manuales), viejas clases medias (empresarios/as, autónomos/as y agricultores/as), obreros/as cualificados/as (manuales cualificados/as, semicualificados/as, capataces y artesanos/as) y obreros/as no cualificados/as (obreros/as de la industria y los servicios y jornaleros/as del campo).

${ }^{6}$ La media ideológica se calcula en base a un eje ideológico, dispuesto en una escala del 1 al 10, donde 1 significa extrema izquierda y 10 , extrema derecha.

7 "Perfil sociológico de los votantes a las cinco formaciones mayores el 26J", disponible en http://javierelzo.blogspot.com.es/2016/05/perfil-sociologico-de-los-votantes-las.html, consultado 04/09/2016.

\section{Referencias}

Cabrera, P. (2014, 30 de junio). ¿Qué supone la irrupción de Podemos en la izquierda? Politikon. Recuperado de http://politikon.es/

Bellucci, P., Garzia, D., y Rubal, M. (2012). ¿Importa Europa en las elecciones europeas? Un modelo explicativo de las elecciones del 2009 al Parlamento Europeo. Revista Española de Investigaciones Sociológicas, 137, 25-41. doi:10.5477/cis/reis.137.25 
Escobar, M., Fernández, E., y Bernardi, F. (2010). Análisis de datos con Stata. Madrid: Centro de Investigaciones Sociológicas.

Estefanía, J. et al. (Dir.) (2015). Informe sobre la democracia 2015. Reformular la política. Madrid: Fundación Alternativas.

Galindo, J., Llaneras, K., Medina, O., San Miguel, J., Simón, P. y Senserrich, R. (2015). La urna rota. La crisis política e institucional del modelo español. Barcelona: Debate.

Gallego, A. (2011). Are more choices in the ballot better? Cross-Nacional and experimental evidence. APSA Annual Meeting Papers.

González, J., y Caínzos, M. (2012). Ciclos políticos y comportamiento electoral de jóvenes y mayores en España, 1979-2011. Panorama Social, 15, 165-179.

Hirschmann, A.O. (1977). Salida, Voz y Lealtad: respuestas al deterioro de empresas, organizaciones y estados. México: Fondo de Cultura Económica.

Lago, I. (1999). Sobrerrepresentación de las zonas rurales y voto conservador en el sistema electoral español. Dereito, 1(8), 81-101.

Laparra, M., y Pérez Eransus, B. (2012). Crisis y fractura social en Europa: causas y efectos en España. Barcelona: Obra Social La Caixa.

Noelle-Neumann, E. (2010). La espiral del silencio: opinión pública: nuestra piel social. Barcelona: Paidós.

Reif, K., y Schmitt, H. (1980). Nine second-order national elections: A conceptual framework for the analysis of European election results. European Journal of Political Research, 8(1), 3-44. doi: 10.1111/j.1475-6765.1980.tb00737.x

Salido, O., y Martín, A. (2007). Las urnas de la precariedad. El anclaje sociolaboral del voto juvenil en el 14-M. Sociedad y Utopía: Revista de Ciencias Sociales, 29, 463-488.

Sánchez-Cuenca, I. (2014). La impotencia democrática. Madrid: Catarata.

Zeisel, H. (1962). Dígalo con números. Madrid: Fondo de Cultura Económica. 


\section{Anexos}

Tabla 1

Recuerdo de voto*hábitat

\begin{tabular}{|c|c|c|c|c|c|c|}
\hline & & & \multicolumn{3}{|c|}{ Hábitat } & \multirow[b]{3}{*}{ Total } \\
\hline & & & $</=$ & Entre 10.000 & $>$ & \\
\hline & & & 10.000 & y 100.000 & 100.000 & \\
\hline \multirow{12}{*}{$\begin{array}{l}\text { Recuerdo de voto } \\
\text { (2015) }\end{array}$} & \multirow{3}{*}{ PP } & Recuento & 333 & 425 & 113 & 1203 \\
\hline & & $\%$ dentro de Hábitat & $38,6 \%$ & $31,6 \%$ & $34,8 \%$ & $33,2 \%$ \\
\hline & & Residuos corregidos & 3,9 & $-1,6$ & $-1,8$ & \\
\hline & \multirow{3}{*}{ PSOE } & Recuento & 310 & 426 & 336 & 1072 \\
\hline & & \% dentro de Hábitat & $35,9 \%$ & $31,6 \%$ & $23,7 \%$ & $29,6 \%$ \\
\hline & & Residuos corregidos & 4,7 & 2,1 & $-6,2$ & \\
\hline & \multirow{3}{*}{ Podemos } & Recuento & 113 & 221 & 339 & 673 \\
\hline & & \% dentro de Hábitat & $13,1 \%$ & $16,4 \%$ & $23,9 \%$ & $18,6 \%$ \\
\hline & & Residuos corregidos & $-4,7$ & $-2,5$ & 6,7 & \\
\hline & \multirow{3}{*}{ C's } & Recuento & 107 & 274 & 297 & 678 \\
\hline & & \% dentro de Hábitat & $12,4 \%$ & $20,4 \%$ & $21,0 \%$ & $18,2 \%$ \\
\hline & & Residuos corregidos & $-5,4$ & 2 & 2,8 & \\
\hline \multirow{2}{*}{ Total } & & Recuento & 863 & 1346 & 1417 & 3626 \\
\hline & & $\%$ dentro de Hábitat & $100,0 \%$ & $100,0 \%$ & $100,0 \%$ & $100,0 \%$ \\
\hline
\end{tabular}

Fuente: Elaboración propia a partir de los datos del CIS 


\section{Valero-Oteo - El Perfil del Votante del Cambio en España}

Tabla 2

Recuerdo de voto (2015)*Nivel de estudios

\begin{tabular}{|c|c|c|c|c|c|c|}
\hline & & & $\begin{array}{c}\text { Estudios } \\
\text { Primarios }\end{array}$ & $\begin{array}{c}\text { Estudios } \\
\text { secundarios }\end{array}$ & $\begin{array}{c}\text { Estudios } \\
\text { superiores }\end{array}$ & Total \\
\hline \multirow{12}{*}{$\begin{array}{l}\text { Recuerdo } \\
\text { de voto } \\
\text { (2015) }\end{array}$} & \multirow{3}{*}{ PP } & Recuento & 403 & 566 & 228 & 1197 \\
\hline & & $\begin{array}{l}\text { \%dentro de } \\
\text { Estudios }\end{array}$ & $43,1 \%$ & $29,9 \%$ & $29,5 \%$ & \multirow[t]{2}{*}{$33,2 \%$} \\
\hline & & $\begin{array}{l}\text { Residuos } \\
\text { tipificados }\end{array}$ & 7,4 & $-4,5$ & $-2,5$ & \\
\hline & \multirow{3}{*}{ PSOE } & Recuento & 292 & 551 & 124 & 1067 \\
\hline & & $\begin{array}{l}\text { \% dentro de } \\
\text { Estudios }\end{array}$ & $40,9 \%$ & $29,1 \%$ & $16,0 \%$ & \multirow[t]{2}{*}{$29,6 \%$} \\
\hline & & $\begin{array}{l}\text { Residuos } \\
\text { tipificados }\end{array}$ & 9,6 &,- 7 & $-9,3$ & \\
\hline & \multirow{3}{*}{ Podemos } & Recuento & 76 & 393 & 199 & 668 \\
\hline & & $\begin{array}{l}\text { \% dentro de } \\
\text { Estudios }\end{array}$ & $8,1 \%$ & $20,7 \%$ & $25,7 \%$ & \multirow[t]{2}{*}{$18,5 \%$} \\
\hline & & $\begin{array}{l}\text { Residuos } \\
\text { tipificados }\end{array}$ & $-9,5$ & 3,6 & 5,8 & \\
\hline & \multirow{3}{*}{$\mathrm{Cs}_{\mathrm{s}}$} & Recuento & 65 & 384 & 222 & 671 \\
\hline & & $\begin{array}{l}\% \text { dentro de } \\
\text { Estudios }\end{array}$ & $6,9 \%$ & $20,3 \%$ & $28,7 \%$ & \multirow[t]{2}{*}{$18,6 \%$} \\
\hline & & $\begin{array}{l}\text { Residuos } \\
\text { tipificados }\end{array}$ & $-10,7$ & 2,7 & 8,1 & \\
\hline \multirow[b]{2}{*}{ Total } & & Recuento & 677 & 1894 & 773 & 3602 \\
\hline & & $\begin{array}{l}\% \text { dentro de } \\
\text { Estudios }\end{array}$ & $100,0 \%$ & $100,0 \%$ & $100,0 \%$ & $100,0 \%$ \\
\hline
\end{tabular}

Fuente: Elaboración propia a partir de los datos del CIS. Estudio n ${ }^{\circ} 3126$ 
Tabla 3

Recuerdo de voto (2015)*Autoubicación Ideológica

\begin{tabular}{|c|c|c|c|c|c|c|c|c|}
\hline & & & \multicolumn{5}{|c|}{ Ideología } & \multirow[b]{2}{*}{ Total } \\
\hline & & & $\begin{array}{c}\text { Extrema } \\
\text { izda. }\end{array}$ & Izquierda & Centro & Derecha & $\begin{array}{c}\text { Extrema } \\
\text { dcha }\end{array}$ & \\
\hline \multirow{12}{*}{$\begin{array}{l}\text { Recuerdo } \\
\text { de voto } \\
\text { (2015) }\end{array}$} & \multirow{3}{*}{ PP } & Recuento & 2 & 18 & 409 & 512 & 150 & 1091 \\
\hline & & $\begin{array}{l}\text { \% dentro de } \\
\text { Ideología }\end{array}$ &, $6 \%$ & $1,6 \%$ & $36,2 \%$ & $84,6 \%$ & $90,4 \%$ & \multirow[t]{2}{*}{$32,7 \%$} \\
\hline & & $\begin{array}{l}\text { Residuos } \\
\text { tipificados }\end{array}$ & $-9,9$ & $-18,2$ & 2,0 & 22,3 & 13,0 & \\
\hline & \multirow{3}{*}{ PSOE } & Recuento & 124 & 665 & 189 & 11 & 1 & \multirow{3}{*}{$\begin{array}{c}990 \\
29,7 \%\end{array}$} \\
\hline & & $\begin{array}{l}\text { \% dentro de } \\
\text { Ideología }\end{array}$ & $40,0 \%$ & $59,2 \%$ & $16,7 \%$ & $1,8 \%$ &, $6 \%$ & \\
\hline & & $\begin{array}{l}\text { Residuos } \\
\text { tipificados }\end{array}$ & 3,3 & 18,1 & $-8,0$ & $-12,6$ & $-6,9$ & \\
\hline & \multirow{3}{*}{ Podemos } & Recuento & 180 & 341 & 105 & 2 & 0 & 628 \\
\hline & & $\begin{array}{l}\text { \% dentro de } \\
\text { Ideología }\end{array}$ & $58,1 \%$ & $30,3 \%$ & $9,3 \%$ &, $3 \%$ &, $0 \%$ & \multirow[t]{2}{*}{$18,8 \%$} \\
\hline & & $\begin{array}{l}\text { Residuos } \\
\text { tipificados }\end{array}$ & 15,9 & 8,9 & $-7,4$ & $-10,5$ & $-5,6$ & \\
\hline & \multirow{3}{*}{$C_{s}^{\prime}$} & Recuento & 4 & 100 & 428 & 80 & 15 & 627 \\
\hline & & $\begin{array}{l}\text { \% dentro de } \\
\text { Ideología }\end{array}$ & $1,3 \%$ & $8,9 \%$ & $37,8 \%$ & $13,2 \%$ & $9,0 \%$ & \multirow[t]{2}{*}{$18,8 \%$} \\
\hline & & $\begin{array}{l}\text { Residuos } \\
\text { tipificados }\end{array}$ & $-7,1$ & $-7,7$ & 14,8 & $-3,2$ & $-2,9$ & \\
\hline \multirow[b]{2}{*}{ Total } & & Recuento & 310 & 1124 & 1131 & 605 & 166 & 3336 \\
\hline & & $\begin{array}{l}\text { \% dentro de } \\
\text { Ideología }\end{array}$ & $100,0 \%$ & $100,0 \%$ & $100,0 \%$ & $100,0 \%$ & $100,0 \%$ & $100,0 \%$ \\
\hline
\end{tabular}

Fuente: Elaboración propia a partir de los datos del CIS. Estudio no 3126 


\section{Valero-Oteo - El Perfil del Votante del Cambio en España}

Tabla 4

Recuerdo de voto (2015)*Grado de interés en la campaña electoral Elecciones Generales 2015

\begin{tabular}{|c|c|c|c|c|c|c|c|}
\hline & & & \multicolumn{4}{|c|}{ Interés campaña electoral elecciones generales de 2015} & \multirow[b]{2}{*}{ Total } \\
\hline & & & $\begin{array}{c}\text { Con } \\
\text { mucho } \\
\text { interés }\end{array}$ & $\begin{array}{c}\text { Con } \\
\text { bastante } \\
\text { interés }\end{array}$ & $\begin{array}{l}\text { Con poco } \\
\text { interés }\end{array}$ & $\begin{array}{l}\text { Con } \\
\text { ningún } \\
\text { interés }\end{array}$ & \\
\hline \multirow{12}{*}{$\begin{array}{l}\text { Recuerdo } \\
\text { de voto } \\
(2015)\end{array}$} & \multirow{3}{*}{ PP } & Recuento & 202 & 469 & 376 & 151 & 1198 \\
\hline & & $\begin{array}{l}\text { \% dentro de Interés } \\
\text { campaña }\end{array}$ & $29,0 \%$ & $34,0 \%$ & $33,2 \%$ & $36,7 \%$ & \multirow[t]{2}{*}{$33,1 \%$} \\
\hline & & Residuos corregidos & $-2,6$ &, 9 &, 1 & 1,7 & \\
\hline & \multirow{3}{*}{ PSOE } & Recuento & 151 & 361 & 399 & 158 & 1069 \\
\hline & & $\begin{array}{l}\% \text { dentro Interés } \\
\text { campaña }\end{array}$ & $21,7 \%$ & $26,2 \%$ & $35,3 \%$ & $38,4 \%$ & \multirow[t]{2}{*}{$29,6 \%$} \\
\hline & & Residuos corregidos & $-5,1$ & $-3,5$ & 5,1 & 4,2 & \\
\hline & \multirow{3}{*}{ Podemos } & Recuento & 201 & 270 & 149 & 52 & 672 \\
\hline & & $\begin{array}{l}\text { \% dentro de Interés } \\
\text { campaña }\end{array}$ & $28,8 \%$ & $19,6 \%$ & $13,2 \%$ & $12,7 \%$ & \multirow[t]{2}{*}{$18,6 \%$} \\
\hline & & Residuos corregidos & 7,8 & 1,2 & $-5,6$ & $-3,3$ & \\
\hline & \multirow{3}{*}{$C^{\prime} s$} & Recuento & 143 & 278 & 207 & 50 & 678 \\
\hline & & $\begin{array}{l}\text { \% dentro de Interés } \\
\text { campaña }\end{array}$ & $20,5 \%$ & $20,2 \%$ & $18,3 \%$ & $12,2 \%$ & \multirow[t]{2}{*}{$18,7 \%$} \\
\hline & & Residuos corregidos & 1,3 & 1,7 & -5 & $-3,6$ & \\
\hline \multirow[b]{2}{*}{ Total } & & Recuento & 697 & 1378 & 1131 & 411 & 3617 \\
\hline & & $\begin{array}{l}\text { \% dentro de Interés } \\
\text { campaña }\end{array}$ & $100,0 \%$ & $100,0 \%$ & $100,0 \%$ & $100,0 \%$ & $\begin{array}{c}100,0 \\
\% \\
\end{array}$ \\
\hline
\end{tabular}

Fuente: Elaboración propia a partir de los datos del CIS. Estudio no 3126 
Tabla 5

Recuerdo de voto (2014)*Nivel de ingresos

\begin{tabular}{|c|c|c|c|c|c|c|c|c|}
\hline & & & \multicolumn{5}{|c|}{ Ingresos } & \multirow[b]{2}{*}{ Total } \\
\hline & & & $<600 €$ & $\begin{array}{l}600- \\
900 €\end{array}$ & $\begin{array}{c}900- \\
1200 €\end{array}$ & $\begin{array}{l}1200- \\
1800\end{array}$ & $\begin{array}{c}>1800 \\
€\end{array}$ & \\
\hline \multirow{12}{*}{$\begin{array}{l}\text { Recuerdo } \\
\text { de voto } \\
(2014)\end{array}$} & \multirow{3}{*}{ PP } & Recuento & 78 & 44 & 40 & 32 & 20 & 214 \\
\hline & & $\%$ dentro de Ingresos & $28,2 \%$ & $36,1 \%$ & $35,7 \%$ & $39,5 \%$ & $42,6 \%$ & $33,5 \%$ \\
\hline & & Residuos corregidos & $-2,5$ &, 7 &, 5 & 1,2 & 1,4 & \\
\hline & \multirow{3}{*}{ PSOE } & Recuento & 121 & 47 & 40 & 18 & 18 & 244 \\
\hline & & $\%$ dentro de Ingresos & $43,7 \%$ & $38,5 \%$ & $35,7 \%$ & $22,2 \%$ & $38,3 \%$ & $38,2 \%$ \\
\hline & & Residuos corregidos & 2,5 &, 1 &,- 6 & $-3,2$ & 0 & \\
\hline & \multirow{3}{*}{ Podemos } & Recuento & 71 & 24 & 29 & 23 & 4 & 151 \\
\hline & & $\%$ dentro de Ingresos & $25,6 \%$ & $19,7 \%$ & $25,9 \%$ & $28,4 \%$ & $8,5 \%$ & $23,6 \%$ \\
\hline & & Residuos corregidos & 1,0 & $-1,1$ & 6 & 1,1 & $-2,5$ & \\
\hline & \multirow{3}{*}{$C^{\prime} s$} & Recuento & 7 & 7 & 3 & 8 & 5 & 30 \\
\hline & & $\%$ dentro de Ingresos & $2,5 \%$ & $5,7 \%$ & $2,7 \%$ & $9,9 \%$ & $10,6 \%$ & $4,7 \%$ \\
\hline & & Residuos corregidos & $-2,3$ &, 6 & $-1,1$ & 2,4 & 2,0 & \\
\hline \multirow[b]{2}{*}{ Total } & & Recuento & 277 & 122 & 112 & 81 & 47 & 639 \\
\hline & & $\%$ dentro de Ingresos & $100,0 \%$ & $100,0 \%$ & $100,0 \%$ & $100,0 \%$ & $\begin{array}{c}100,0 \\
\%\end{array}$ & $\begin{array}{c}100,0 \\
\% \\
\end{array}$ \\
\hline
\end{tabular}

Fuente: Elaboración propia a partir de los datos del CIS. Estudio n ${ }^{\circ} 3028$ 


\section{Valero-Oteo - El Perfil del Votante del Cambio en España}

Tabla 6

Recuerdo de voto (2014)*Valoración de la situación económica personal

\begin{tabular}{|c|c|c|c|c|c|c|c|c|}
\hline & & & \multicolumn{5}{|c|}{ Valoración de la situación económica personal } & \multirow[b]{2}{*}{ Total } \\
\hline & & & $\begin{array}{c}\text { Muy } \\
\text { buena }\end{array}$ & Buena & Regular & Mala & $\begin{array}{l}\text { Muy } \\
\text { mala }\end{array}$ & \\
\hline \multirow{12}{*}{$\begin{array}{l}\text { Recuerdo } \\
\text { de voto } \\
\text { (2014) }\end{array}$} & \multirow{3}{*}{ PP } & Recuento & 4 & 115 & 131 & 29 & 7 & 286 \\
\hline & & $\begin{array}{l}\text { \% dentro situación } \\
\text { económica personal }\end{array}$ & $50,0 \%$ & $45,6 \%$ & $34,3 \%$ & $24,6 \%$ & $16,3 \%$ & \multirow[t]{2}{*}{$35,6 \%$} \\
\hline & & Residuos corregidos & 9 & 4,0 &,- 7 & $-2,7$ & $-2,7$ & \\
\hline & \multirow{3}{*}{ PSOE } & Recuento & 0 & 70 & 144 & 51 & 20 & 285 \\
\hline & & $\begin{array}{l}\text { \% dentro de situación } \\
\text { económica personal }\end{array}$ &, $0 \%$ & $27,8 \%$ & $37,7 \%$ & $43,2 \%$ & $46,5 \%$ & \multirow[t]{2}{*}{$35,5 \%$} \\
\hline & & Residuos corregidos & $-2,1$ & $-3,1$ & 1,2 & 1,9 & 1,6 & \\
\hline & \multirow{3}{*}{ Podemos } & Recuento & 4 & 55 & 91 & 33 & 14 & 197 \\
\hline & & $\begin{array}{l}\text { \% dentro de situación } \\
\text { económica personal }\end{array}$ & $50,0 \%$ & $21,8 \%$ & $23,8 \%$ & $28,0 \%$ & $32,6 \%$ & \multirow[t]{2}{*}{$24,5 \%$} \\
\hline & & Residuos corregidos & 1,7 & $-1,2$ &,- 4 &, 9 & 1,3 & \\
\hline & \multirow{3}{*}{$\mathrm{C}$ 's } & Recuento & 0 & 12 & 16 & 5 & 2 & 35 \\
\hline & & $\begin{array}{l}\text { \% dentro de situación } \\
\text { económica personal }\end{array}$ &, $0 \%$ & $4,8 \%$ & $4,2 \%$ & $4,2 \%$ & $4,7 \%$ & \multirow[t]{2}{*}{$4,4 \%$} \\
\hline & & Residuos corregidos &,- 6 &, 4 &,- 2 &,- 1 &, 1 & \\
\hline \multirow[b]{2}{*}{ Total } & & Recuento & 8 & 252 & 382 & 118 & 43 & 803 \\
\hline & & $\begin{array}{l}\% \text { dentro de situación } \\
\text { económica personal }\end{array}$ & $100,0 \%$ & $100,0 \%$ & $100,0 \%$ & $100,0 \%$ & $100,0 \%$ & $100,0 \%$ \\
\hline
\end{tabular}

Fuente: Elaboración propia a partir de los datos del CIS. Estudio no 3028

Irene Valero-Oteo es estudiante del programa de Doctorado

Sociedad, Política y Cultura de la Universidad del País Vasco, España

Dirección de contacto: Departamento de Sociología II. Facultad de

Ciencias Sociales y de la Comunicación. Universidad del País Vasco.

Barrio Sarriena, s/n -48940- Leioa (Bizkaia), España. Email:

irenevaleroteo@gmail.com 